\title{
Possibilities and limitations of steam distillation-extraction as a pre-concentration technique for trace analysis of organics by capillary gas chromatography
}

Citation for published version (APA):

Rijks, J. A., Curvers, J. M. P. M., Noij, T. H. M., \& Cramers, C. A. M. G. (1983). Possibilities and limitations of steam distillation-extraction as a pre-concentration technique for trace analysis of organics by capillary gas chromatography. Journal of Chromatography, 279(1), 395-407. https://doi.org/10.1016/S0021-9673(01)93639-8

DOI:

10.1016/S0021-9673(01)93639-8

Document status and date:

Published: 01/01/1983

Document Version:

Publisher's PDF, also known as Version of Record (includes final page, issue and volume numbers)

Please check the document version of this publication:

- A submitted manuscript is the version of the article upon submission and before peer-review. There can be important differences between the submitted version and the official published version of record. People interested in the research are advised to contact the author for the final version of the publication, or visit the $\mathrm{DOI}$ to the publisher's website.

- The final author version and the galley proof are versions of the publication after peer review.

- The final published version features the final layout of the paper including the volume, issue and page numbers.

Link to publication

\footnotetext{
General rights

- You may freely distribute the URL identifying the publication in the public portal. follow below link for the End User Agreement:

www.tue.nl/taverne

\section{Take down policy}

If you believe that this document breaches copyright please contact us at:

openaccess@tue.nl

providing details and we will investigate your claim.
}

Copyright and moral rights for the publications made accessible in the public portal are retained by the authors and/or other copyright owners and it is a condition of accessing publications that users recognise and abide by the legal requirements associated with these rights.

- Users may download and print one copy of any publication from the public portal for the purpose of private study or research.

- You may not further distribute the material or use it for any profit-making activity or commercial gain

If the publication is distributed under the terms of Article 25fa of the Dutch Copyright Act, indicated by the "Taverne" license above, please 
POSSIBILITIES AND LIMITATIONS OF STEAM DISTILLATION-EXTRACTION AS A PRE-CONCENTRATION TECIINIQUE FOR TRACE ANALYSIS OF ORGANICS BY CAPILLARY GAS CHROMATOGRAPHY

\author{
J. RIJKS*, J. CURVERS, Th. NOY and C. CRAMERS
}

Eindhoven University of Technology, Department of Chemistry, Laboratory of Instrumental Analysis, P.O. Box 513, $5600 \mathrm{MB}$ Eindhoven (The Netherlands)

\title{
SUMMARY
}

The quantitative performance of steam distillation-extraction was investigated for different types of organic substances at concentrations ranging from tens of parts per million to parts per billion (parts per $10^{5}$ to $10^{9}$ ). A theoretical model is introduced that describes the recovery of different classes of organic compounds as a function of the process time. The effect of variations of some process factors predicted theoretically are in good agreement with the experimental results. A $100 \%$ recovery is obtained within 20 min for most substances. Enrichment factors between 50 and 200 and recoveries corresponding to a standard deviation of $10 \%$ can be achieved in many applications.

\section{INTRODUCTION}

Trace analysis of organics in various types of liquid and solid samples, at concentrations down to parts per $10^{9}$ and $10^{12}$ levels, is becoming increasingly important. Current and proposed demands of governmental regulations in the field of environmental research, quality control of food, beverages, drinking water, etc., are the main reasons for this trend.

Because of the complexity of the samples, high-resolution gas chromatography (GC) is the most attractive method for the determination of trace organic compounds with sufficient volatility. Detailed information about both the quantitative and qualitative composition can be obtained within a reasonable time; qualitative analysis, if required, can be effected in combination with mass spectrometry (MS).

Detection limits depend on the sensitivity of the detector, the sample capacity and efficiency of the column and the compatibility of the sample introduction system and the input bandwidth with the column efficiency. The detection limits can be decreased by improvement of the detector sensitivity, a decrease in the noise level and a reduction in the peak width. Another approach is the pre-concentration of the components of interest prior to GC analysis. Various methods, procedures and devices for trace enrichment have been reported. Unfortunately, little has been reported on evaluation and comparison of these methods and systems for different classes of substances 
and concentration levels. Therefore, an extensive study of the performance of various methods for the isolation or concentration of traces of organic compounds with sufficient volatility for GC analysis was started in our laboratory a few years ago.

In this paper, we report our studies on steam distillation-extraction, a technique introduced by Likens and Nickerson in $1964^{1}$. In a continuous process the condensing water vapour is extracted by the condensing solvent vapour, yielding a high extraction efficiency. Both the water and the solvent are recirculated. Their device was modified by Maarse and Kepner ${ }^{2}$. Godefroot and co-workers ${ }^{3,4}$ developed a micro-version for analytical applications and reported recoveries of $80-100 \%$ for compounds such as alcohols, ketones and chlorinated pesticides within $1 \mathrm{~h}$ of processing. The method was applied to the analysis of essential oils ${ }^{3}$. Comparative studies of different pre-concentration techniques ${ }^{5,6}$ have shown that steam distillation-extraction (SDE) is a uniform, useful and representative method. As the volume of the aqueous sample is much larger than the volume of the extraction solvent, enrichment factors between 50 and 200 can be achieved.

We have studied the effects of several experimental factors on the recovery, the process rate and the enrichment factor using model mixtures with constituents covering a wide range of volatilities, functional groups and concentrations. A theoretical model is introduced that predicts the recovery as a function of the process time and its dependence on a number of experimental factors for a specific problem at concentrations ranging from tens of parts per million to parts per billion (parts per $10^{5}$ to $10^{9}$ ).

\section{THEORY}

A theoretical model was developed in order to predict the applicability of SDE and the effect of various process- and compound-dependent factors on the recovery and the process rate. The flows and concentrations during the SDE process are presented schematically in Fig. 1.

To simplify the mathematical treatment of the SDE process, the following assumptions are made: (1) all volumes and flows of liquids and vapours remain constant during the process $(\mathrm{d} V / \mathrm{d} t=0)$; (2) within all phases there is ideal mixing and thermodynamic equilibrium exists at every stage; (3) no losses occur via the top of the condensation tube $\mathrm{K}\left(F_{1} C_{1}^{*}=0\right)$, and this was confirmed experimentally; and (4) liquidliquid extraction takes place at the cold-finger, and no further exchange of solutes occurs in the phase separation compartment $\mathrm{C}$. Most probably this assumption is also valid, as it was observed with SDE processing of iodine in water. If not, the effect on the rate of recovery will be negligibly small.

Starting from the mass balances, the relationships of the thermodynamic equilibrium of the gas-liquid distribution and some simplifications following from the assumptions above, the SDE process can be described by the following basic equations:

$$
\begin{aligned}
& \frac{\mathrm{d} C_{\mathrm{e}}}{\mathrm{d} t}=\frac{1}{\tau_{\mathrm{e}}} \cdot C_{\mathrm{e}}^{*}-\frac{K_{\mathrm{e}}}{\tau_{\mathrm{e}}} \cdot C_{\mathrm{e}} \\
& \frac{\mathrm{d} C_{\mathrm{w}}}{\mathrm{d} t}=\frac{1}{\tau_{\mathrm{w}}} \cdot C_{\mathrm{w}}^{*}-\frac{K_{\mathrm{w}}}{\tau_{\mathrm{w}}} \cdot C_{\mathrm{w}}
\end{aligned}
$$




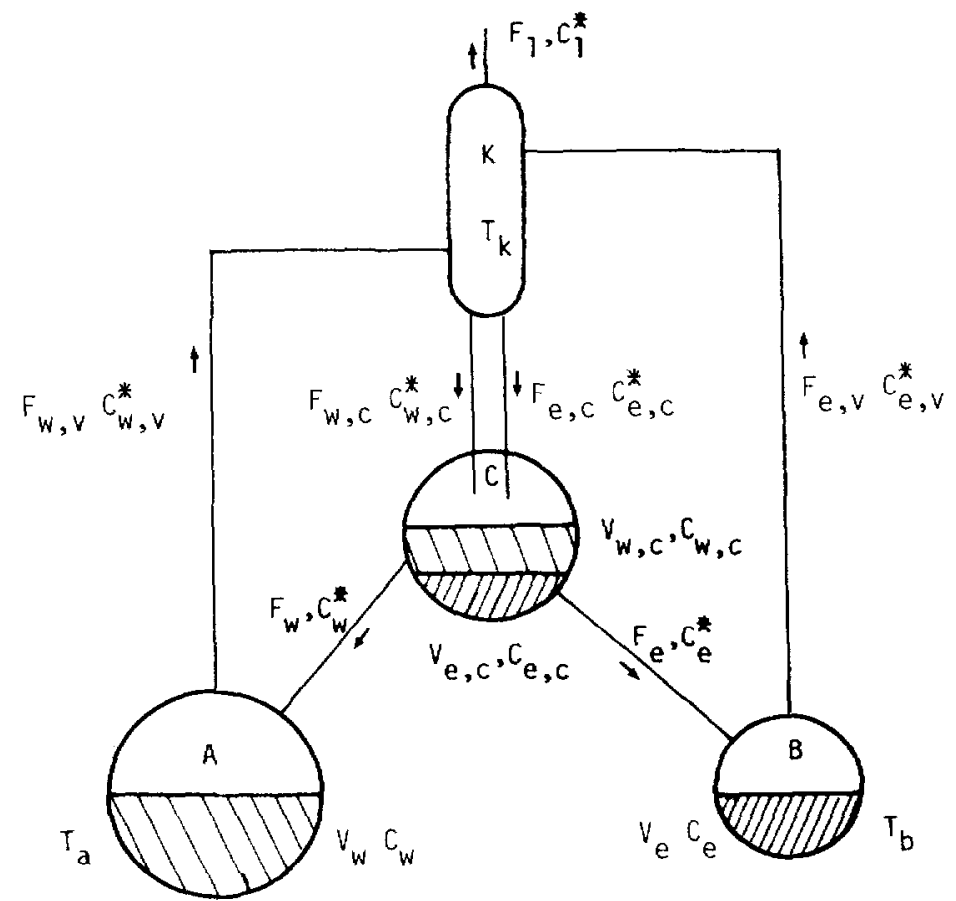

Fig. 1. Schematic diagram of flows and concentrations during SDE processing, $F=$ gas or liquid flow-rate; $V=$ volume; $C=$ mass concentration in a non-flowing medium; $C^{*}=$ mass concentration in a flowing medium; $T=$ temperature. Subscripts: $\mathrm{w}=$ water; $\mathrm{e}=$ extraction solvent; $\mathrm{v}=$ vapour phase $; \mathrm{c}=$ condensed phase $;$ $=$ loss.

$$
\begin{aligned}
& \frac{\mathrm{d} C_{\mathrm{e}}^{*}}{d t}=\frac{1}{\tau_{\mathrm{e}, \mathrm{c}}}\left(C_{\mathrm{e}, \mathrm{c}}^{*}-C_{\mathrm{e}}^{*}\right) \\
& \frac{\mathrm{d} C_{\mathrm{w}}^{*}}{d t}=\frac{1}{\tau_{\mathrm{w}, \mathrm{c}}}\left(C_{\mathrm{w}, \mathrm{c}}^{*}-C_{\mathrm{w}}^{*}\right) \\
& K_{\mathrm{w}} C_{\mathrm{w}}+F K_{\mathrm{e}} C_{\mathrm{e}}=C_{\mathrm{w}, \mathrm{c}}^{*}+F C_{\mathrm{e}, \mathrm{c}}^{*} \\
& K=\frac{C_{\mathrm{e}, \mathrm{c}}^{*}}{C_{\mathrm{w}, \mathrm{c}}^{*}}
\end{aligned}
$$

where $\tau_{\mathrm{e}}$ and $\tau_{\mathrm{e}, \mathrm{c}}$ are the mean residence times of the solvent in compartments $\mathrm{B}$ and $\mathrm{C}$, respectively, $\tau_{\mathrm{w}}$ and $\tau_{\mathrm{w}, \mathrm{c}}$ are the mean residence times of the water in compartments $\mathrm{A}$ and C, respectively, $K_{\mathrm{e}}$ and $K_{\mathrm{w}}$ are the gas-liquid distribution coefficients for a component at the temperatures in the compartments $\left(T_{\mathrm{b}}\right.$ and $\left.T_{\mathrm{a}}\right)$ and $F$ is the ratio of the volume flows of solvent to water $\left(F_{\mathrm{e}} / F_{\mathrm{w}}\right)$. As the solution of this set of equations would result in a fourth-order differential equation with complex constants, two further simplifications are made: (1) the extraction coefficient $K$ is assumed to approach infinity, 
which holds for components with a large affinity for the solvent; and (2) the gas-liquid distribution coefficient $K_{\mathrm{e}}$ is negligibly small for non-volatile organics with a large affinity for the solvent. The transport of the sample constituents will be delayed if $K$ does not approach infinity. If $K_{\mathrm{e}}$ does not approach zero, the maximum achievable recovery will be less than $100 \%$.

Now the equations can be simplified as follows:

$$
\begin{aligned}
& \frac{\mathrm{d} C_{\mathrm{e}}}{\mathrm{d} t}=\frac{1}{\tau_{\mathrm{e}}} \cdot C_{\mathrm{e}}^{*} \\
& \frac{\mathrm{d} C_{\mathrm{w}}}{\mathrm{d} t}=-\frac{K_{\mathrm{w}}}{\tau_{\mathrm{w}}} \cdot C_{\mathrm{w}} \\
& \frac{\mathrm{d} C_{\mathrm{e}}^{*}}{d t}=\frac{1}{\tau_{\mathrm{e}, \mathrm{c}}}\left(C_{\mathrm{e}, \mathrm{c}}^{*}-C_{\mathrm{e}}^{*}\right) \\
& K_{\mathrm{w}} C_{\mathrm{w}}=F C_{\mathrm{e}, \mathrm{c}}^{*}
\end{aligned}
$$

Rearrangement of the combined eqns. 8 and 10 yields an expression for $C_{\mathrm{c}}^{*}$ as a function of time. Substitution of this in the exponential equivalent of eqn. 9 yields, after combination with eqn. 7 and integration, the following expression for the concentration of a solute in the extraction solvent:

$$
C_{\mathrm{e}}=\frac{\tau_{\mathrm{w}}}{\tau_{\mathrm{e}} F} \cdot C_{\mathrm{w}_{0}}\left(\frac{\tau_{\mathrm{w}}}{K_{\mathrm{w}}}-\tau_{\mathrm{e}, \mathrm{c}}\right)^{-1}\left\{\frac{\tau_{\mathrm{w}}}{K_{\mathrm{w}}}\left[1-\exp \cdot\left(-\frac{K_{\mathrm{w}}}{\tau_{\mathrm{w}}}\right)\right]-\tau_{\mathrm{e}, \mathrm{c}}\left[1-\exp \cdot\left(-\frac{1}{\tau_{\mathrm{e}, \mathrm{c}}} \cdot t\right)\right]\right\}
$$

where $C_{\mathrm{w}_{0}}$ is the concentration of the component in the original aqueous sample.

The recovery is the ratio of the amount of a compound in the extraction solvent in compartment B to the amount originally present in the sample, which can be expressed as

$$
R=\frac{C_{\mathrm{e}} V_{\mathrm{e}}}{C_{\mathrm{w} 0} V_{\mathrm{w}}}=\frac{1}{C_{1}-C_{2}}\left\{C_{1}\left[1-\exp \cdot\left(-\frac{t}{C_{1}}\right)\right]-C_{2}\left[1-\exp \cdot\left(-\frac{t}{C_{2}}\right)\right]\right\}
$$

where

$$
\begin{aligned}
& C_{1}=\frac{\tau_{\mathrm{w}}}{K_{\mathrm{w}}}=\frac{V_{\mathrm{w}}}{F_{\mathrm{w}}}\left(\frac{p_{\mathrm{tot}}}{p_{t}^{0} \gamma_{i}^{N}}\right) T_{a} \\
& C_{2}=\tau_{\mathrm{e}, \mathrm{c}}=\frac{V_{\mathrm{e}, \mathrm{c}}}{F_{\mathrm{e}}}
\end{aligned}
$$

Because of the simplifying assumptions made, this expression is true only for compounds with a large affinity for the extracting solvent. 


\section{EXPERIMENTAL}

\section{Stock solutions of synthetic mixtures}

In order to investigate the effect of vapour pressure, activity coefficient and structure on the recovery, the following stock solutions were prepared:

(1) "hydrocarbon mix", a mixture of normal hydrocarbons with carbon numbers ranging from 7 to 26 , boiling points between 98 and $400^{\circ} \mathrm{C}$ and at concentrations of about $100 \mathrm{ppm}(\mathrm{w} / \mathrm{v})$;

(2) "volatiles mix", composed of relatively volatile components with boiling points between 56 and $111^{\circ} \mathrm{C}$ and at concentrations of about $4 \%(\mathrm{w} / \mathrm{v})$;

(3) "phenolic mix", a mixture of phenol and mono- and dimethyl-substituted phenols with boiling points between 180 and $225^{\circ} \mathrm{C}$, and at concentrations of about $0.2 \%(\mathrm{w} / \mathrm{v})$ per component; and

(4) "multimix", a mixture that contains substances with different functional groups, e.g., alcohols, ketones and aromatics, with boiling points between 111 and $223^{\circ} \mathrm{C}$ and at concentrations of about $1 \%(\mathrm{w} / \mathrm{v})$ per component.

The required concentrations were obtained by addition of an appropriate volume of the original solution or diluted stock solution to the aqueous sample.

\section{Equipment for steam distillation-extraction}

The design of the equipment used in our studies with dichloromethane, a solvent with a density greater than that of water $\left(\rho_{\mathrm{e}}>\rho_{\mathrm{w}}\right)$, is shown in Fig. 2.

\section{Gas chromatography}

Although various types of instruments were used throughout the investigations for the GC analysis, most studies were performed on a Packard-Becker 427 instrument (United Technologies Packard, Delft, The Netherlands). The gas chromatograph was equipped with a laboratory-built splitter, provided with a quartz-glass liner. The split vent line was provided with a magnetic valve to permit splitless injections. Splitless injection with a low-boiling solvent such as dichloromethane requires an initial oven temperature as low as $25^{\circ} \mathrm{C}$. To achieve such a low temperature the oven was left open during sample transfer into the column. The injector and detector temperatures were usually $250^{\circ} \mathrm{C}$; however, the detector temperature was sometimes increased to $275^{\circ} \mathrm{C}$, depending on the boiling points of the components. Helium was used as the carrier gas. CP-Sil-5 fused-silica columns (Chrompack, Middelburg, The Netherlands) with a length of $25 \mathrm{~m}$ and I.D. 0.25 or $0.32 \mathrm{~mm}$ were used. The chromatographic data were processed by a SP-4000 data system (Spectra-Physics, Santa Clara, CA, U.S.A.).

\section{Procedure}

Each SDE analysis was performed in the following way ( $c f$, Fig. 2): $1.5 \mathrm{ml}$ of solvent and $1.5 \mathrm{ml}$ of doubly distilled water were introduced into the separation chamber C, so that both side-arms, D and E, were filled. Then the solvent flask B ( $2 \mathrm{ml}$ ) was filled with $1 \mathrm{ml}$ of solvent, containing an internal standard at an apropriate concentration. One cleaned boiling chip was added and then the solvcnt container was heated by means of a water-bath at $54^{\circ} \mathrm{C}$ when dichloromethane (analytical-reagent grade, Merck, Darmstadt, F.R.G.) was used. 

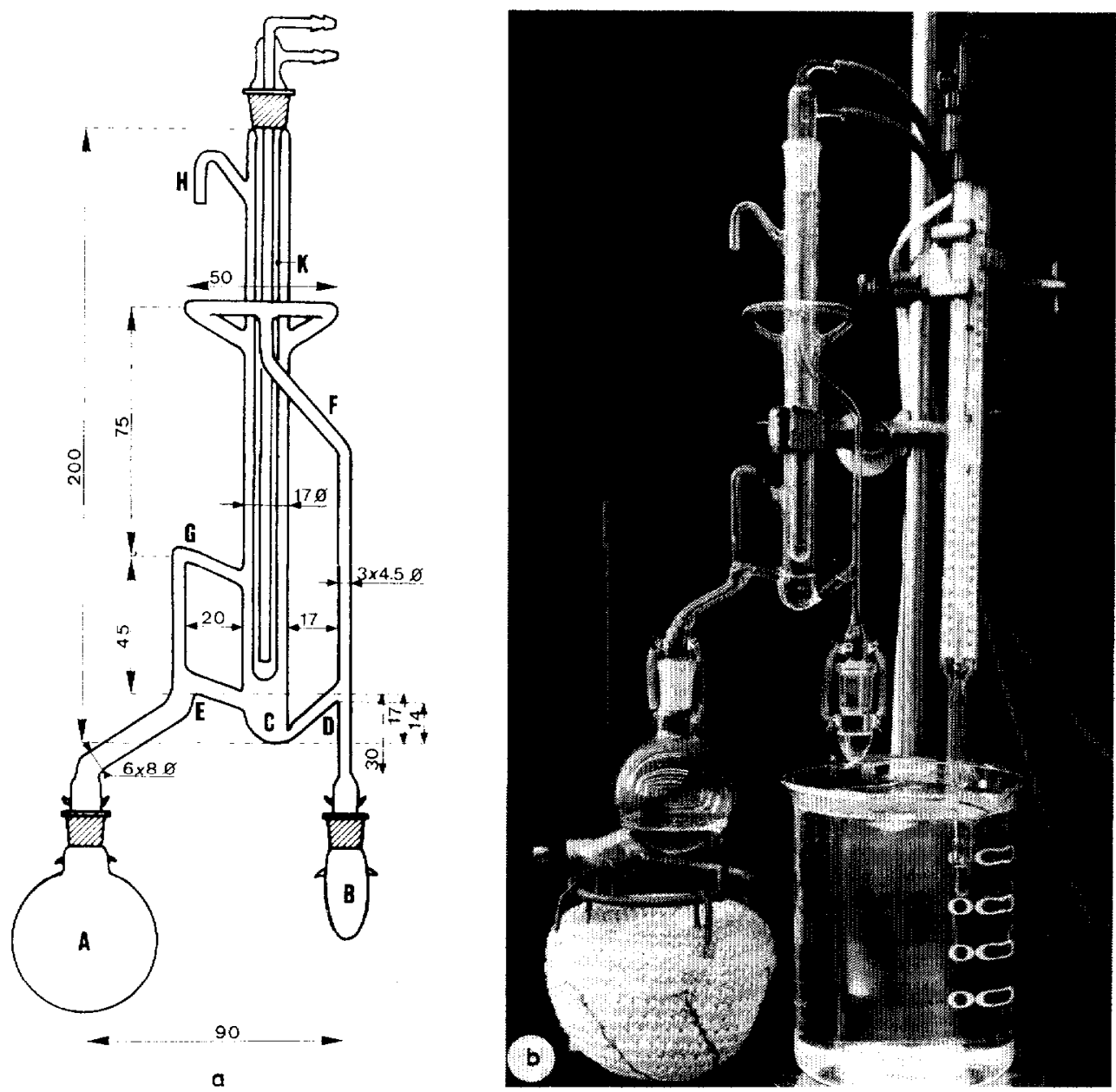

Fig. 2. Equipment for SDE with dichloromethane. (a) Design and dimensions of the apparatus (dimensions in millimeters); (b) experimental set-up.

A known volume of stock solution was added to 10 or $50 \mathrm{ml}$ of doubly distilled water in the sample flask $A$, then some cleaned boiling chips were introduced. The sample container was heated by a heating mantle. The water for the cold-finger was cooled to $5^{\circ} \mathrm{C}$ by passing it through melting ice.

Boiling of the extractiong solvent was started 10-15 min before the boiling of the water. The SDE process time was measured from the moment the condensation front of the water vapour reached the side-arm connection $\mathrm{E}$. After the required time had elapsed, the boiling of the water was stopped, but the reflux of the solvent was continued for a further $10 \mathrm{~min}$. In this way, the remaining organics in $\mathrm{C}$ were transferred to B. The extract in B $(0.5-1 \mathrm{ml})$ was poured into a 1-ml glass container, stoppered with a PTFE cap. Finally, $1 \mu \mathrm{l}$ of this extract was injected into the gas chromatograph. 
The recovery (the amount of the component extracted from the water sample) was calculated relative to the internal standard. The internal standard was added to the solvent prior to SDE processing in order to correct for changes in the solvent volume in $B$ due to evaporation or addition from $C$. The concentrations of the compounds of interest and the internal standard are affected in the same way, and this results in an unchanged ratio of the peak areas.

The boiling chips were cleaned by repeatedly boiling them in acetone and dichloromethane and subsequently drying them in an oven at $150^{\circ} \mathrm{C}$. For every SDE analysis new boiling chips were used. The SDE apparatus was cleaned by rinsing it with water and acetone and then heating it in an oven at $80-100^{\circ} \mathrm{C}$ for several hours. The recovery was calculated as the ratio of the peak areas in the extract and the original sample relative to the internal standard.

\section{RESULTS AND DISCUSSION}

\section{Design of the apparatus}

In order to make processing more convenient and reliable, the SDE apparatus described by Godefroot $e \mathrm{al}_{.}{ }^{3}$ was slightly modified. The distance between containers A and B (cf., Fig. 2) was enlarged to $90 \mathrm{~mm}$ to facilitate their heating. The return tube was broadened to $6 \mathrm{~mm}$ at the steam distillation side, to allow backflow of the water without staggering. The length of the condensation tube (cold-finger $\mathrm{K}$ ) between the two vapour inlets was increased to $75 \mathrm{~mm}$, to minimize possible losses. An enlarged view of the separation chamber C overflows is presented in Fig. 3. The distance between these overflows is critical, particularly when unattended processing is required. The optimal distance can be calculated according to

$$
\frac{a-b}{a-c}=1-\frac{\rho_{\mathrm{w}}}{\rho_{\mathrm{e}}}
$$

where $\rho_{\mathrm{w}}$ and $\rho_{\mathrm{c}}$ are the densities of water and solvent, respectively. This follows straightforwardly from the equality of hydrostatic pressures at horizontal levels of the liquids in the separation chamber and overflows.

The position of the boundary layer between the phases $(b)$, which obviously depends only on the density of the solvent and the vertical distance of the sharp edges

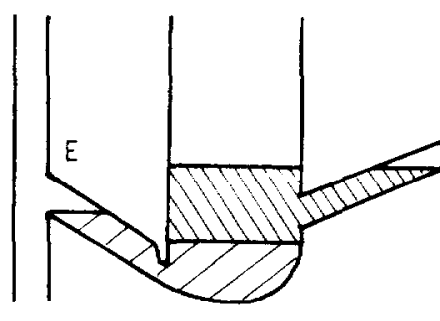

A

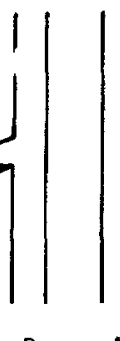

A

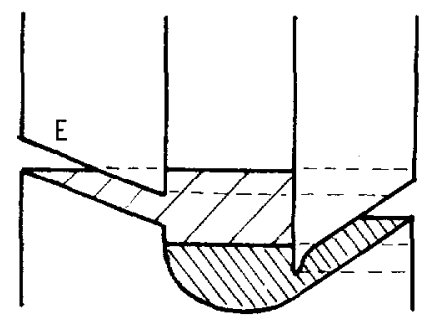

b) $P_{e}>P_{w}$

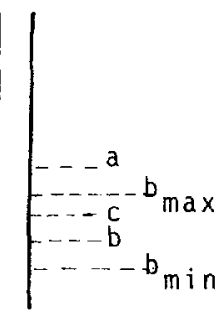

B

a) $P_{e}<P_{w}$

Fig. 3. Schematic design of the separation chamber and the water and solvent overflows. 
of the overflows $(a, c)$, is critical. Too large a distance between these edges will cause water to press all of the solvent, and finally water, into the solvent flask B. The smaller the differences between the densities of the solvent and water, the smaller the tolerance of the distances between the sharp edges of the overflows $(a, c)$ becomes. When $\rho_{\mathrm{w}}$ $<<\rho_{\mathrm{e}}$, this tolerance is large. The difference in height of the lower edges of the overflows can be slightly adjusted by rotation of the SDE apparatus out of its vertical position.

For solvents with a density lower than that of water (Fig. 3a), the sample container A must be connected to the lowest overflow. This cannot be carried out simply by changing the solvent and sample flask, because the solvent vapour must enter the condensation tube at a higher position than the water vapour in order to achieve an efficient extraction and to avoid sample losses.

\section{Reference mixtures and calibration}

Reference mixtures are prepared by addition of a measured amount of one of the stock solutions (see Experimental) to $1 \mathrm{ml}$ of the extraction solvent (which contains a corresponding concentration of the internal standard). A second identical amount of stock solution is used for SDE after addition to $50 \mathrm{ml}$ of water. An identical amount of extracting solvent with an identical concentration of internal standard is used for the extraction. After GC analysis of both the extract and the reference mixture, the recovery can be calculated as the ratio of the areas of corresponding peaks, relative to the internal standard.

\section{Reproducibility}

A 20-ppb concentration of the "phenolic mix" was selected for measuring the reproducibility of the method. This mixture covers a wide range of recoveries, which has an unfabourable influence on the reproducibility. As shown in Table I, an average standard deviation between 5 and $10 \%$ can be expected for polar compounds that show a strong interaction with water. Variations due to the preparation of the sample, the SDE process and the GC analysis are included in these figures. Variations in the composition of the reference mixtures were excluded.

\section{TABLE I}

RECOVERIES AND RELATIVE STANDARD DEVIATIONS FOR PHENOL AND MONO- AND DIMETHYL-SUBSTITUTED PHENOLS

Processing time, 30 min.; concentration, $20 \mathrm{ppb}$ per component; number of measurements, 4 .

\begin{tabular}{llll}
\hline Compound & Boiling point $\left({ }^{\circ} \mathrm{C}\right)$ & Recovery $(\%)$ & RSD (\%) \\
\hline Phenol & 182 & 17 & 12 \\
$o$-Cresol & 191 & 56 & 6.4 \\
$m$ - + p-Cresol & 203 & 31 & 7.7 \\
2,6-Dimethylphenol & 212 & 97 & 2.4 \\
2,5-Dimethylphenol & 211 & 72 & 5.5 \\
3,5-Dimethylphenol & 220 & 45 & 9.2 \\
2,3-Dimethylphenol & 218 & 57 & 6.1 \\
3,4-Dimethylphenol & 225 & 30 & 8.0
\end{tabular}


As expected the reproducibility will be considerably better for less polar constituents, with a recovery approaching $100 \%$ within a relatively short processing time (e.g., less than $15 \mathrm{~min}$ ).

\section{Accuracy}

The accuracy of the method was initially tested by 30 -min processing of aqueous "multimix" solutions at concentrations down to $20 \mathrm{ppb}$ per component. Recoveries approaching $100 \%$ were observed for every component in the mixture. These results suggest that significant losses due to venting of the internal standard or the sample constituents or adsorption on the boiling chips can be neglected. In order to detect whether losses via the open air connection $\mathrm{H}$ ( $c f$. , Fig. 2) take place for more volatile substances, aqueous stock solutions of the "volatiles mix" were processed for $30 \mathrm{~min}$ at $10 \mathrm{ppm}$ concentrations. In the vapours vented via the top $(\mathrm{H})$, which were collected in cooled dichloromethane, none of the components could be detected. Adsorption on the boiling chips, which was determined by addition of 20 chips to a 1 ppm "multimix" solution and GC analysis of aliquots of the solution after $10 \mathrm{~min}$ to $24 \mathrm{~h}$, appeared negligible.

\section{Comparison of theoretical and experimental recoveries}

The recovery can be calculated as a function of time (eqn. 12) if $C_{1}$ and $C_{2}$, are known. The smaller these constants are, the larger is the recovery. For non-polar components with a relatively high volatility $\left(C_{1}<<C_{2}\right)$ the recovery becomes independent of vapour pressure, sample volume and water flow and is affected only by the process conditions. For polar or non-volatile components $\left(C_{1}>>C_{2}\right)$, the process time must be increased considerably in order to achieve reasonable recoveries.

Some comparative figures for theoretical and experimental recoveries are given in Fig. 4 for components with different structures, vapour pressures and polarities.

Approximate values of activity coefficients, gas-liquid distribution coefficients and the corresponding values of $C_{1}$ and $C_{2}$ are given in Table II. The activity coefficients were calculated either from the water solubility at $100^{\circ} \mathrm{C}$ or by extrapolation to infinite dilution from tabulated activity coefficients ${ }^{7}$. The average residence times for water $(5900 \mathrm{sec}$ for a $50-\mathrm{ml}$ sample) and dichloromethane $(270 \mathrm{sec})$ in the separation chamber were determined experimentally.
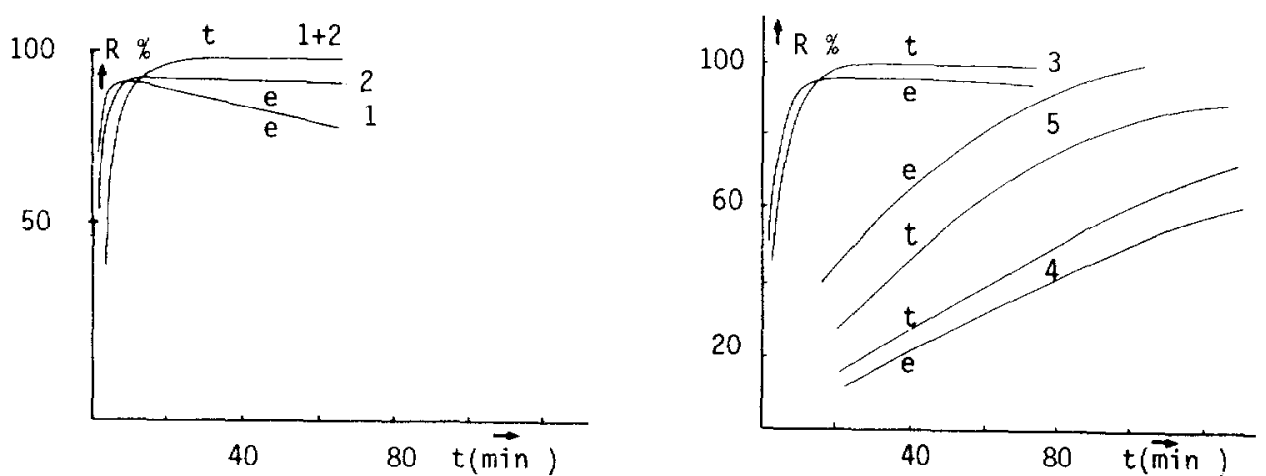

Fig. 4. Comparison of theoretical (t) and experimental (e) recoveries. $1=$ Toluene; $2=0$-dichlorobenzene; $3=1$-heptanone; $4=$ phenol; $5=$ o-cresol. 
TABLE II

APPROXIMATE VALUES OF ACTIVITY COEFFICIENTS, GAS-LIQUID DISTRIBUTION COEFFICIENTS AND THE CORRESPONDING VALUES OF $C_{1}$ AND $C_{2}$ AT $100^{\circ} \mathrm{C}$

\begin{tabular}{lrrrr}
\hline Compound & \multicolumn{1}{c}{$\gamma_{i}^{\mathrm{v}} \mathrm{K}_{\mathrm{w}}$} & \multicolumn{1}{c}{$C_{1}(\mathrm{sec})$} & $C_{2}(\mathrm{sec})$ \\
\hline Toluene & 1000 & 724 & 8.2 & 270 \\
1-Heptanol & 2300 & 98 & 61 & 270 \\
o-Dichlorobenzene & 26000 & 1900 & 3.0 & 270 \\
Phenol & 28 & 1.0 & 6000 & 270 \\
$o$-Cresol & 84 & 1.9 & 3200 & 270 \\
\hline
\end{tabular}

The experimental and theoretical recovery values and profiles are in good agreement. The observed differences can be explained by uncertainties in the calculated activity coefficients and the experimental residence times. As expected smaller experimental recoveries are observed for phenol than predicted by the theory. This is because the model does not apply for polar compounds $(K \rightarrow \infty)$. However, the deviations are relatively small. The fact that at low processing times experimental recoveries are larger

TABLE III

RECOVERIES OF PHENOL AND SOME MONO- AND DISUBSTITUTED PHENOLS FOR CONCENTRATIONS BETWEEN $20 \mathrm{ppb}$ AND $10 \mathrm{ppm}$ AFTER 30-min SDE PROCESSING

\begin{tabular}{lcll}
\hline \multirow{2}{*}{ Compound } & \multicolumn{2}{c}{ Recovery $(\%)$} & \\
\cline { 2 - 4 } & $10 \mathrm{ppm}$ & $500 \mathrm{ppb}$ & $20 \mathrm{ppb}$ \\
\hline Phenol & 21 & 21 & 17 \\
o-Cresol & 63 & 63 & 56 \\
m- + p-Cresol & 35 & 34 & 31 \\
2,6-Dimethylphenol & 100 & 97 & 97 \\
2,5-Dimethylphenol & 79 & 48 & 72 \\
3,5-Dimethylphenol & 49 & 62 & 57 \\
2,3-Dimethylphenol & 64 & 33 & 30 \\
3,4-Dimethylphenol & 35 & & \\
\hline
\end{tabular}
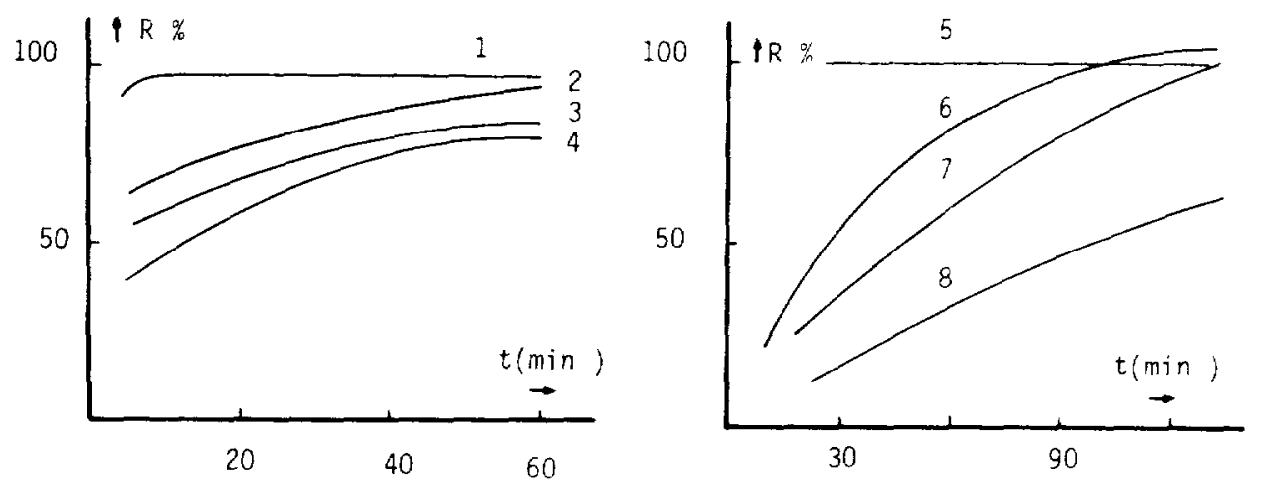

Fig. 5. Recovery versus process time: $1=n-\mathrm{C}_{9} ; 2=n-\mathrm{C}_{22} ; 3=n-\mathrm{C}_{24} ; 4=n-\mathrm{C}_{26} ; 5=2,6$-dimethylphenol; $6=$ o-cresol; $7=3$,4-dimethylphenol; $8=$ phenol. 
than the calculated data can probably be explained by the delayed start of the time measurement (see Experimental). The transport of the solvent and water vapours and, thus, the extraction of the sample constituents is already started before the start of the time measurement $(t=0)$. In spite of these differences, the theoretical model can be used for a better understanding and prediction of the effects of some experimental factors on the recovery.

Effect of concentration. According to eqn. 12, the recovery is independent of the concentration of components in the sample. Experimental results with $50-\mathrm{ml}$ aqueous samples of different concentrations of phenols are presented in Table III. In agreement with the theoretical model, no significant effect of concentration on the recovery can be observed for concentrations between $20 \mathrm{ppb}$ and $10 \mathrm{ppm}$.

Effect of process time. From the theoretical model, it follows that the process time has a considerable influence on the recovery, particularly for polar substances or components with a high boiling point $\left[C_{1}>C_{2}\right.$, and thus $\left.R=1-\exp .\left(-t / C_{1}\right)\right]$. Therefore, long process times will be required in order to achieve reasonable recoveries. This was investigated and confirmed with aqueous stock solutions of phenols ("phenolic mix") and n-alkanes ("hydrocarbon mix") at concentrations of 20 ppb per component. Some representative results are given in Fig. 5.

For volatile or non-polar substances, in agreement with the theory $\left[C_{1}<<C_{2}\right.$ and thus $R=1$-exp. $\left(-t / C_{2}\right)$ ], complete recoveries and short processing times $(e . g$., $10-15 \mathrm{~min})$ are established for different classes of substances. This is illustrated for some representative components of $10 \mathrm{ppm}$ "multimix" solutions in Fig. 6 . All the components of this "multimix solution" reached their maximum recovery (>93\%) within $15 \mathrm{~min}$. For components with the lowest boiling points (toluene, $n$-octane, $n$-hexyl chloride) the recovery decreases slightly with increasing processing times.

As a representative example, Fig. 7 shows some comparative chromatograms of reference solutions, prepared from a "multimix"stock solution and a Eucalyptus oil sample without and after SDE processing for $30 \mathrm{~min}$. In agreement with the quantitative results above, it is hardly possible to observe any difference between the chromatograms of identical samples before and after SDE processing of both the "multimix" reference solution and the Eucalyptus oil.

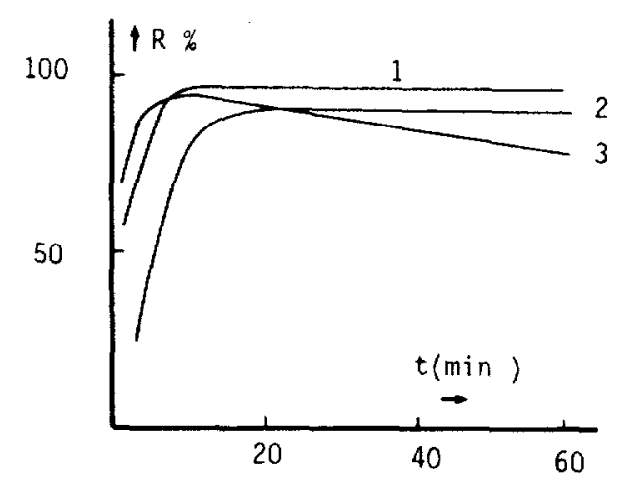

Fig. 6. Recovery versus time for some representative components of a diluted "multimix solution" with concentrations of 10 ppm per component: $1=2$-nonanone; $2=$ benzylacetone; $3=$ toluene. 

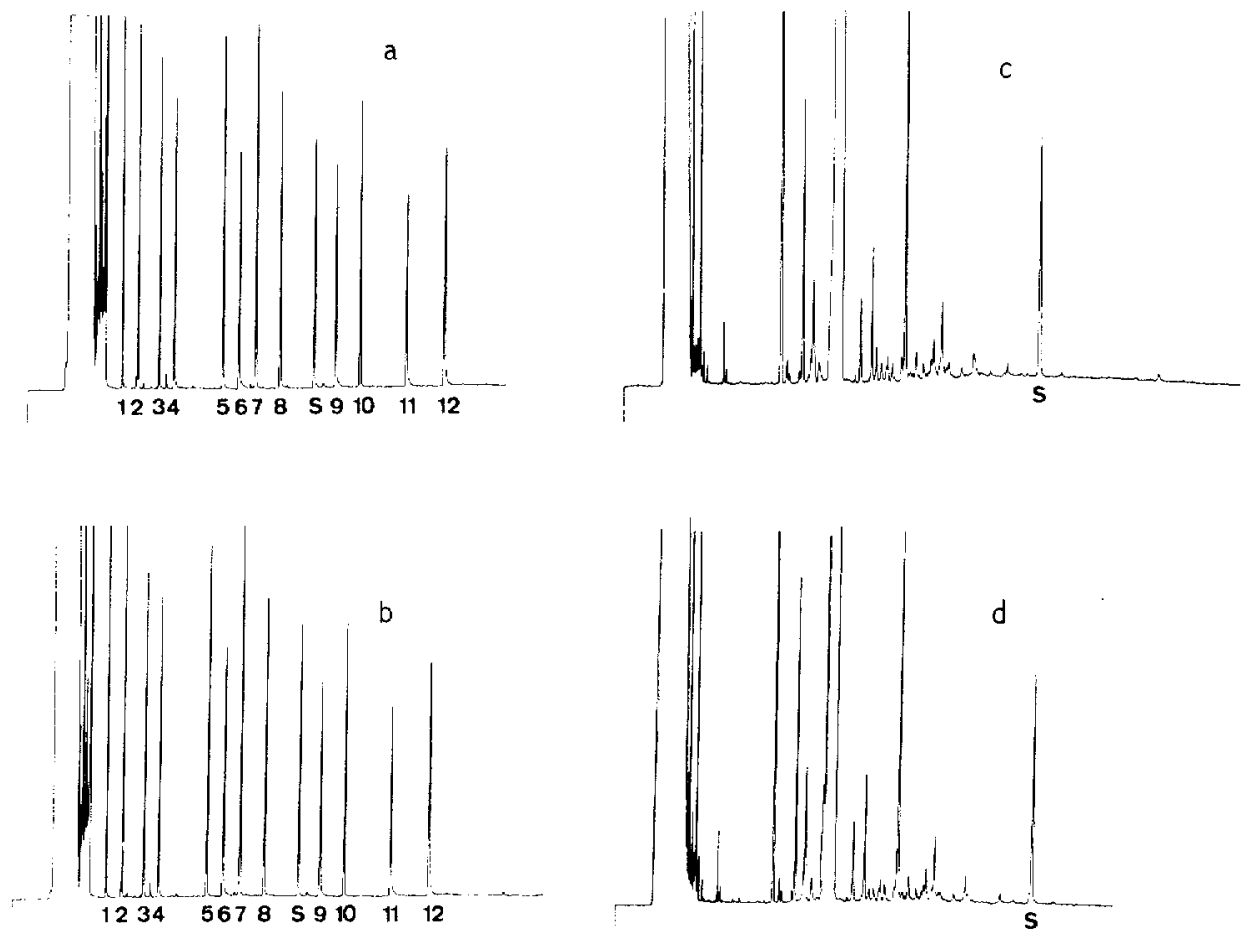

Fig. 7. Comparative chromatograms of identical samples of reference solutions prepared from a diluted "multimix" stock solution and Eucalyptus oil and their extracts after SDE processing for 30 min. (a) "Multimix" reference solution of $1 \mathrm{ppm}(\mathrm{w} / \mathrm{v})$ per component in dichloromethane; (b) the corresponding extract; (c) Eucalyptus oil reference solution of $0.2 \%$ in dichloromethane; (d) the corresponding extract. Internal standard: $n$-octyl chloride, 1 ppm (w/v), for (a) and (b) and $n$-tridecane for (c) and (d). GC instrument, HP-5880; column, CP-3IL-5 Chrompack, $25 \mathrm{~m} \times 0.25 \mathrm{~mm}$ I.D., fused silica; $1 \mu$ l splitless injection. Temperature programme: (a) and (b), $25^{\circ} \mathrm{C}$ for $30 \mathrm{sec}$ at $5^{\circ} \mathrm{C} / \mathrm{min}$, increased to $50^{\circ} \mathrm{C}$, isothermal for $3 \mathrm{~min}$, increased to $150^{\circ} \mathrm{C}$ at $5^{\circ} \mathrm{C} / \mathrm{min}$; (c) and (d), as for (a) and (b) but without the isothermal part. Peaks: $1=$ toluene; $2=n$-octane; $3=n$-hexyl chloride; $4=3$-heptanone; $5=p$-chlorotoluene; $6=1$-heptanol; $7=1,2,3$-trimethylbenzene; $8=o$-dichlorobenzene; $9=2$-nonanone; $10=n$-undecane; $11=1$-nonanol; 12 = benzylacetone.

Effect of solvent. The rate of recovery for polar compounds not only depends on their activity coefficients in the aqueous sample, but also on their distribution between the two liquid phases. Therefore, this extraction coefficient $(K)$ and also the gas-liquid distribution coefficient $\left(K_{\mathrm{e}}\right)$ in the extraction solvent will be affected by the type of solvent. Therefore, diluted "multimix" and "phenolic mix" solutions at concentrations of $200 \mathrm{ppb}$ were SDE processed for periods between 5 and $60 \mathrm{~min}$. Dichloromethane and $n$-pentane were used as extraction solvents. From the results, some of the most interesting examples of which are presented in Fig. 8, it can be concluded that for non-polar or weakly polar substances, dichloromethane and $n$-pentane do not yield significant different recoveries. For phenols, however, $n$-pentane appears less efficient, which results in long processing times. In addition, owing to the large activity of phenols in the refluxing $n$-pentane, this results in recirculation of the phenols in the apparatus so that complete recovery will not be achieved. 


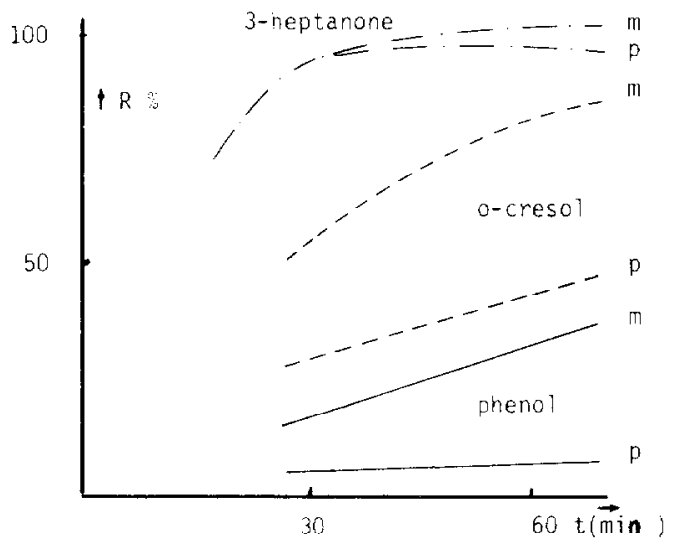

Fig. 8. Influence of the extraction solvent for some representative components of "phenolic mix" and "multimix" stock solutions at concentrations of 200 and $100 \mathrm{ppb}$, respectively; $\mathrm{p}=n$-pentane; $\mathrm{m}=$ dichloromethane.

\section{CONCLUSION}

Considering the quantitative recovery, the process rate and the enrichment factor, SDE is a versatile and promising method for the trace analysis of organics in liquid or solid samples prior to capillary GC or GC-MS.

\section{REFERENCES}

1 S. Likens and G. Nickerson, Proc. Amer. Soc. Brew. Chem., (1964) 5.

2 H. Maarse and R. Kepner, J. Agr. Food Chem., 18 (1970) 1095.

3 M. Godefroot, P. Sandra and H. Verzele, J. Chromatogr., 203 (1981) 325.

4 M. Godefroot, M. Stechele, P. Sandra and M. Verzele, J. High Resolut. Chromatogr. Chromatogr. Commun., 5 (1982) 75 .

5 W. Jennings and M. Filsoof, J. Agr. Food. Chem., 25 (1977) 440.

6 T.L. Peters, Anal. Chem., 54 (1982) 1913.

7 K. Schäfer and E. Lax (Editors), Landolt Bor̈nstein, Zahlenwerte und Funktionen aus Physik, Chemie, Astronomie, Geophysik and Technik, Part II.2, Springer, Berlin, 6th ed., 1960. 